\title{
MANUSCRITOS, INÉDITOS, CUADERNOS Y CORRESPONDENCIA: LA CREACIÓN DE LAS MUERTAS DE JORGE IBARGÜENGOITIA
}

\section{MANUSCRIPTS, UNPUBLISHED DRAFTS, NOTEBOOKS AND PERSONAL CORRESPONDENCE: BEHIND THE WRITING OF JORGE IBARGÜENGOITIA'S LAS MUERTAS}

\author{
Alejandro LÁmbarry \\ Benemérita Universidad Autónoma de Puebla \\ alambarry.ffyl@gmail.com \\ orcid: 0000-0003-3299-5914
}

\begin{abstract}
Resumen: El propósito de este artículo es analizar el proceso de creación de la novela Las muertas: su primera formulación en 1965, su reescritura de 1966 a 1975 y su versión final, que Ibargüengoitia escribe en 1976. El análisis se centra en el manuscrito inédito de El libro de las Poquianchis, la correspondencia personal del autor con Joy Laville, sus cuadernos de trabajo y la versión final de la novela, publicada en Joaquín Mortiz. Nuestras conclusiones versan sobre la voz del narrador, la estructura y el final del relato, el pacto de lectura y la poética del autor.
\end{abstract}

Palabras clave: literatura mexicana; Jorge Ibargüengoitia; Las muertas; archivo; manuscritos.

Abstract: Our main objective in this article is to analyze the creative process that went into the writing and rewriting of Ibargüengoitia's novel Las muertas during the years 1965-1976. To this end we offer a study of the novel's first unpublished draft, written in 1965 and entitled El libro de las Poquianchis, of the author's personal correspondence with Joy Laville, his working notebooks and the final published version of the novel, completed in 1976 . We draw conclusions regarding the narrator's voice, the structure and ending of the novel, the author-reader contract, and the author's poetics.

Keywords: Mexican literature; Jorge Ibargüengoitia; The dead girls; archive; manuscripts.

Recepción: $1^{\circ}$ de marzo de 2019; aceptación: 5 de febrero de 2020. 
El proceso de creación de la novela Las muertas fue para Jorge Ibargüengoitia el más largo y tortuoso de su carrera como escritor. A diferencia de sus otras novelas, cuya redacción tomó de uno a tres años como máximo, Las muertas cuenta al menos con cuatro borradores en un período de escritura de trece años ${ }^{1}$. El primer borrador, que lleva como título El libro de las Poquianchis, se escribió en 1965, un año después de que la prensa nacional divulgara con amarillismo el caso de las hermanas González Valenzuela. De este primer escrito a la versión impresa, publicada en Joaquín Mortiz en 1977, en la colección Nueva Narrativa Hispánica, hay cambios significativos de gran importancia en cada texto. Nuestro propósito en este trabajo consiste en analizar tales cambios según cinco elementos formales y de contenido: la voz del narrador, la estructura del relato, el pacto de lectura, el final del relato y la poética del autor. Deseamos también aportar un estado de la cuestión de la recepción crítica, periodística y académica de la obra para reflexionar sobre su contribución literaria.

Analizar los borradores de una obra publicada es labor que suele cumplir con fines teleológicos, en que las versiones previas cobran importancia por lo que podrían revelar en su estructura y contenido con respecto a la versión final, la impresa. Esto ha cambiado con los estudios, por ejemplo, de Graciela Goldchluck, para quien no hay una versión final ni definitiva; se pueden estudiar, por lo mismo, una versión impresa y

${ }^{1}$ Es posible establecer un estimado del tiempo de creación de sus novelas con los comentarios del propio Ibargüengoitia y los borradores de sus novelas, que se conservan en la Biblioteca de Manuscritos de la Universidad de Princeton. La escritura de Los relámpagos de agosto debió realizarse en 1963, ya que el primer borrador concluido tiene fecha del 2 de septiembre de ese año y el Premio Casa de las Américas se concedió a esta obra en el mes de abril de 1964. Maten al león se escribió, de igual manera, en un año, según lo atestiguan dos borradores concluidos con fecha de marzo 1969, cuyo texto es muy semejante al de la versión final, con algunos cambios menores en una que otra palabra y en la ortografía. El primer borrador de Estas ruinas que ves es de 1974 y, como advertiremos más adelante, en 1973 el autor renunció de nueva cuenta al plan de novela de Las muertas, así que es posible afirmar que la creación de Estas ruinas que ves no le tomó más de un año. Para su novela Dos crimenes, tenemos un cuaderno de notas con fecha de diciembre de 1977. Hay borradores de la novela correspondientes a 1978 y 1979. Así pues, elaborar esta novela le tomó casi tres años. Por último, Los pasos de López cuenta con borradores desde 1979, hasta su publicación en 1981. Por lo tanto, sus primeras tres novelas debieron haberle tomado, en promedio, un año de creación; las últimas dos, de dos a tres años, como máximo. 
otra en borrador como dos obras distintas, o dos variaciones con valor independiente ${ }^{2}$. Se trata, en su caso, de encontrar nuevas interpretaciones y desafíos de escritura para trabajos que solían dejarse olvidados en el archivo. En esta línea deseamos incluir nuestra investigación con el fin de comprender en su totalidad los desafíos creativos y la manera en que tres figuras autorales (el Ibargüengoitia de 1965, el de 1970 y el de 1977) lo resolvieron ${ }^{3}$. En lugar de establecer un criterio de calidad, nos interesa realizar tres lecturas de obras que implican una gran originalidad creativa y una novedad formal en la tradición literaria mexicana.

Las obras son El libro de las Poquianchis de 1965 y la versión final publicada de Las muertas. Para las versiones llevadas a cabo entre los años de 1970 a 1976 contamos con los cuadernos de Ibargüengoitia, a la par de su escritura y la correspondencia con Joy Laville, quien fuera su compañera sentimental ${ }^{4}$. De esta manera, a un primer acercamiento comparativo entre dos borradores completos agregamos, en un segundo momento, una discusión teórica sobre la poética del autor reflejada en lo que podríamos llamar su taller de escritura: cuadernos y correspondencia en los que Ibargüengoitia revisaba y replanteaba elementos que consideraba esenciales en la estructura, el lenguaje y la trama de sus novelas.

\section{EL LIBRO DE LAS POQUIANCHIS}

Las hermanas González Valenzuela fueron acusadas en 1964 de haber asesinado en distintos momentos, y de varias maneras, a cerca de 91 personas, en su mayoría prostitutas que trabajaban bajo sus órdenes. La noticia atrajo la atención de la prensa, sobre todo la amarillista, según muestra Alicia Muñoz (2008).

${ }^{2}$ Véase Goldchluck 2011 para un estudio comparativo de los manuscritos de Manuel Puig. Acercamientos de tipo semejante a la obra de Mario Bellatin pueden encontrarse en CUARTAS 2018 y LÁMBARRY y EsCOBAR 2018.

${ }^{3}$ Nos referimos a una figura autoral ya que analizamos, a la par de los textos creativos, los cuadernos personales que el autor utilizaba para evaluar su obra. Estos cuadernos tienen críticas, correcciones y comentarios de la obra narrativa, que nos permiten visualizar la figura autoral de Ibargüengoitia.

${ }^{4}$ El libro de las Poquianchis permanece inédito y, al igual que los cuadernos y cartas de Ibargüengoitia, se encuentra en la Biblioteca de Rare Books and Speciall Collections de la Universidad de Princeton. 
Durante el juicio y el encarcelamiento de las hermanas González Valenzuela, el periódico Alarma (más tarde Alarma!) mezcló los supuestos hechos con los rumores para narrar una magnificada historia de horror. Las Poquianchis quedaron representadas como "hermanas del diablo", "hienas", "hiena que echaba espuma por la boca" (Muñoz 2008, p. 80). El encabezado de una foto en la que aparecen detrás de las rejas lee: "Encerradas como lo que son: ¡ratas!” (p. 81)

Tras el escándalo, la nota de las hermanas González Valenzuela captó la atención de Ibargüengoitia; no sólo era una historia extraordinaria, sino que había sucedido en su estado natal, Guanajuato. Según su propio testimonio, y el de su amiga Margarita Villaseñor, consiguió en el curso del año 1964 el expediente judicial del caso ${ }^{6}$. Al leerlo, reparó en que las autoridades locales habían acelerado el proceso judicial debido a la presión mediática y política. Había, además, una gran confusión con la identificación de los cadáveres, los criminales y las distintas versiones de la historia. Irregularidades en el expediente y mentiras en los periódicos: la combinación perfecta para hacerse de un chivo expiatorio. Y si bien las hermanas González Valenzuela pudieron haber asesinado a sus trabajadoras, la verdad sobre lo sucedido y la implicación de otras personas en el asunto quedaron, por siempre, veladas. Así al menos lo entendió Ibargüengoitia, quien decidió recrear su versión de lo sucedido con una idea clara en mente: revertir la representación sencilla y burda del periodismo amarillista con el retrato de una sociedad empobrecida, hipócrita y corrupta.

Entre marzo y abril de 1965 -como consta en la primera página del manuscrito inédito- Ibargüengoitia escribió una

${ }^{5}$ Si hacemos un breve repaso de otros periódicos de la época, notamos que a pesar de que siguieron una línea más moderada que Alarma, no faltaron comentarios como los de Bernardo Ponce (1964) en Excélsior: "Que todo el peso de las leyes caiga sobre los seres demoníacos que han violado las leyes divinas y humanas en forma inusitada y escandalosa". Y en El Heraldo, de León, Guanajuato, se refirieron a las presuntas asesinas invariablemente como "las diabólicas" (cf. Birth commemoration). Se desconoce, por cierto, el origen del apodo de "las Poquianchis".

${ }^{6}$ El padre de Margarita Villaseñor era en la época presidente de la Suprema Corte de Justicia del Estado de Guanajuato. Entre otras labores, "revisaba el caso de las «Poquianchis». No sé quién, o no quiero decirlo, sacó copia de los alegatos y Jorge comenzó su obra. Pretendía hacer una obra dramática, pero Dios escribe derecho en reglones torcidos" (VILlaseñor 2002, p. 401). 
suerte de crónica de lo sucedido que tituló El libro de las Poquianchis. Utilizó la misma voz narrativa autobiográfica de lenguaje coloquial y aparentemente sencilla, irónica y con un humor desacralizador que había usado en sus cuentos de La ley de Herodes $^{7}$. Para probar que se trataba de una historia basada en hechos reales, expuso desde el primer capítulo sus fuentes: el expediente del juicio, una copia simple de la declaración de Juan González Martínez e información publicada en los periódicos nacionales y estatales. Pero apenas mencionó las fuentes, introdujo agravantes; la principal era el expediente:

lo tuve en mis manos no más de diez horas, casi por accidente y al principio de la investigación... Sólo los defensores tienen acceso legal al expediente, así es que yo lo vi, como quien dice, de contrabando... Por esta razón, mi libro no tiene carácter de documento, sino que es un conjunto de opiniones de las que sólo yo soy responsable (Early, p. 4).

En la historia de un crimen, el narrador empezaba su historia confesando otro crimen, el de la sustracción de documentos de un proceso penal.

El texto de Ibargüengoitia cumple con la correspondencia entre el nombre del narrador y el del autor, que es para Philippe Lejeune (1996) la convención principal del género de la autobiografía $^{8}$. Ambos, narrador y autor, son además profesores de literatura y escritores. La crónica inicia con una nota claramente autobiográfica:

Entre octubre de 1963 y fines de enero de 1964 viví en California. Durante esta época me enteré por los periódicos del caso del Violador de los Guantes Verdes... Además, en esta época ocurrió la muerte del Presidente Kennedy. / -En México la gente es muy buena -decía yo-, estas cosas nunca suceden. / Con estas

7 De esta voz narrativa, Huberto Batis (1979) destacó que Ibargüengoitia había renovado el género de la autobiografía con el humor de su estilo "personalísimo"; la suya era "una autobiografía, a diez años luz de las escritas por los jóvenes de Empresas Editoriales, tan solemnes" (cf. Clippings).

${ }^{8}$ Lejeune escribe: "L'autobiographie (récit racontant la vie de l'auteur) suppose qu'il y ait identité de nom entre l'auteur (tel qu'il figure, par son nom sur la couverture), le narrateur du récit et le personnage dont on parle. C'est là un critère très simple, qui définit en même temps que l'autobiographie tous les autres genres de la littérature intime (journal, autoportrait, essai)" (pp. 23-24). 
convicciones regresé a México y cuando salí del aeropuerto vi un periódico que decía: "16 MUJERES ASESINADAS POR LAS POQUIANCHIs" y una información procedente de León, Guanajuato, que está cerca de donde yo nací (Early draft, p. 1).

El libro de las Poquianchis utiliza las convenciones de la autobiografía para establecer un puente entre la realidad y la ficción que permite, a su vez, leer este texto bajo una clave de verdad. Según Ivan Jablonka (2016), la historia y la literatura son disciplinas afines porque ambas utilizan la narración como un método de conocimiento, si bien en la historia tenemos los medios de verificación que respaldan lo escrito, mientras que en la literatura se busca únicamente la verosimilitud. Ibargüengoitia utiliza recursos formales de ambas disciplinas para legitimar su escrito y, a la vez, cuestionar las fronteras entre la ficción y la historia. Por un lado, cita el expediente del caso, la investigación hemerográfica e incluso realiza visitas a los lugares del crimen: el burdel de Lagos de Moreno y la casa de San Francisco del Rincón, donde estuvieron encerradas durante meses las víctimas: "estos burdeles eran para licenciados, para hacendados, para diputados, para industriales, para comerciantes. Como quien dice, burdeles «para gente decente»" (Early draft, p. 25) ${ }^{9}$. Por otro lado, a estos elementos de una voz más histórica les agrega la voz irónica, lúdica y personal de su narrador autobiográfico. Hay aquí una conciencia de ambos géneros (ficción e historia), con sus recursos formales (autobiografía o crónica novelada), lo que cobrará gran importancia en el transcurso de su proyecto creativo.

Gracias a esta labor de investigación y a su esfuerzo por seguir los hechos expresados en testimonios y fuentes orales, descubrimos que el verdadero antagonista de su crónica, El libro de las Poquianchis, es el periodismo amarillista o de opinión -bajo la sombra de la justicia mexicana. El periodismo sacrificó

${ }^{9}$ Ibargüengoitia es en este sentido más estricto que los escritores del nuevo periodismo, quienes justificaron, bajo el argumento de la creación, el olvido de sus fuentes y la recreación de acontecimientos apenas sugeridos en los documentos o entrevistas. Así al menos lo afirma CHARlotte LANGE (2009, p. 4): "Capote's overall objective was to create a narrative that employed novelistic techniques without compromising factual accuracy (Plimpton: no pagination). However, the factual correctness of the nonfiction novel is questionable given the author's reliance on memory as practiced by Capote". 
las fuentes por la historia: un melodrama en el que las Poquianchis eran diabólicas, bestias, animales, y los antros donde trabajaban, lugares de "orgías para los labriegos y los arrieros de la región, y francachelas para las autoridades" ( $i d$.). Pero una visita a los propios burdeles y una mínima revisión de las fotos permitieron a Ibargüengoitia descubrir que éstos eran lugares elegantes, limpios y bien surtidos. Antes de que concluyeran las declaraciones de las supuestas víctimas: "Los seis cadáveres encontrados se convirtieron, ya en las mesas de redacción, en $16,26,50$ y 100" (p. 48). El periodismo amarillista hundió a las acusadas, de manera que el abogado de oficio que las defendió -el que tenían contratado y había trabajado para ellas durante años, no se atrevió a presentarse-declaró al periódico Excélsior: "Si a mí me preguntan: ¿Qué opina usted de la sentencia de tantos años que se acaba de dictar en contra de sus defendidas?, contestaría de inmediato: demasiado pequeña. Soy defensor de oficio y ni modo" (p. 66).

Además de la prensa, la justicia mexicana fue responsable de armar un expediente que, en lugar de aclarar, complicó los hechos y de realizar un juicio claramente sesgado e injusto para las víctimas. Era imposible saber por la lectura del expediente cuántas personas y quiénes murieron: no hay claridad ni siquiera en los nombres, que cambian en tres versiones distintas:

Para María de Jesús fueron Ernestina, María y Flor. Según las listas aceptadas por el Juez, las muertas fueron Berta Molina, María Flores y Ernestina. En el expediente, un personaje N. reconoce las fotografías como de: Ernestina Mancilla Alcalá, a quien decían Rosa, María Flores o sea Zenaida, Santa Ríos o Zoila o Elvira Ríos y María Flores, que murió loca por los golpes que le propinaban María de Jesús y Delfina (p. 60).

En el expediente se asienta que sólo se encontraron seis cadáveres. Según la declaración de "un individuo que no da su nombre -por temor a las Poquianchis" (p. 49), éstas habían incinerado a varias mujeres y fetos humanos antes de arrojarlos a un barranco llamado Garganta del Diablo. Los periódicos hicieron varias expediciones al lugar, pero sólo encontraron tierra, rocas y las cenizas de algo que parecía una fogata. Sin embargo, en el semanario Alarma se publicó que la "Garganta del Diablo era... uno de los panteones particulares de las hermanas González Valenzuela, en donde gozaban observan- 
do cómo las aves de rapiña despedazaban cadáveres de jóvenes mujeres que mataban a palos por serles inservibles en su «negocio»" (Muñoz 2008, p. 83). No hubo cadáveres, pero sí testigos que afirmaban haber participado en los crímenes; el hecho era a todas luces sospechoso: "En las declaraciones referentes al cadáver abandonado en las cercanías de Jalostotitlán, parece que hay una ansia de decir iyo estuve allí!... Lo que falta de pruebas, sobra de confesiones" (Early draft, pp. 77-78). Había en el expediente un acta notarial realizada después de la clausura del "Guadalajara de Noche" de Lagos de Moreno, en la cual se consignaba que, a la pregunta de si estaban en dicho lugar por libre albedrío, todas las trabajadoras afirmaron sin excepción que sí lo estaban. Para Ibargüengoitia narrador, era evidente que el hecho de ofrecer en el juicio una indemnización a las víctimas fue clave para que las firmantes cambiaran de opinión y, ante notario, se convirtieran de trabajadoras en damnificadas: "las indemnizaciones fueron, o cuando menos, pueden haber sido un factor importantísimo en el proceso; un factor que funcionó en contra de los intereses de las Poquianchis" (p. 79).

Ibargüengoitia escribe con una voz narrativa lúdica y el profesionalismo de un cronista que consulta documentos, archivos y realiza visitas al lugar del crimen. A diferencia de la prensa, describe a las asesinas y a las muertas como seres humanos llevados a condiciones extremas de resistencia, a quienes el gobierno ha fallado en educar al nivel más básico, y que el periodismo, coludido con el poder, usa como chivos expiatorios. Para desacralizar esta historia, que adquirió tintes satánicos y profanos, narra situaciones en tono casual pero con un claro potencial dramático, rayano en lo cómico:

algunas pupilas habían sido enviadas poco tiempo antes de un burdel llamado "Río Rita" que está en San Juan del Río y que es propiedad de María Montes. Por estas pupilas, las Poquianchis recibieron la cantidad de $\$ 600$... Ahora bien, los equipos de foot ball hacen, abiertamente, tratos semejantes y nadie ha protestado nunca. Dejo que se vaya contigo tal jugador que tengo contratado y tú me das tanto. Cosa muy legal y muy justa (p. 16).

$\mathrm{Al}$ encarcelar a las Poquianchis, se describió con detalle sus condiciones de vida, junto con su dieta, que era "caldo de frijol y cinco tortillas". Ibargüengoitia salta directo a la conclusión: "Es decir, que las Poquianchis han sido condenadas a cuarenta 
años de cárcel por, entre otras cosas, dar a sus pupilas el mismo trato que reciben los presos en la Cárcel Municipal de León, Guanajuato" (p. 64).

Así pues, el Ibargüengoitia de 1965 establece culpas durante y al final de su relato: acusa al periodismo amarillista de poco profesionalismo, al gobernador del estado de Guanajuato "por darle una solución moral a un problema económico" (p. 87) y al gobierno mexicano por la situación de ignorancia y desprotección en la que mantiene a sus clases marginadas. En uno de los últimos capítulos de su texto, "La región donde pasó todo", narra su visita a la casa que fue escenario de los crímenes:

Fui caminando unos cuantos metros hasta llegar frente a la única construcción de dos pisos que tiene un letrero que dice todavía "Guadalajara de Noche". Me detuve y estuve mirando el lugar. Vi una luz mortecina a través de un cristal opaco. Me acerqué y oí voces. No supe qué decían, ni cuántas personas eran. Después me alejé pensando si serían cuidadoras o si serían otras treinta y tantas prostitutas que habían llegado allí a refugiarse de una persecución en otro Estado (p. 91).

La persecución del gobierno a las clases marginadas, las condiciones denigrantes en las que éstas viven, huyendo de la ley, se repetiría una y otra vez, de manera incesante, hasta que se reconozca la complejidad del problema. Hay un claro pesimismo en este final que no encontramos en otros textos suyos, salvo en la versión final de Las muertas.

\section{CORRESPONDENCIA Y CUADERNOS PERSONALES}

El primer apunte autobiográfico que hace alusión al proceso creativo de Las muertas se encuentra en su columna "En primera persona", publicada en Vuelta. En el texto "Memorias de novelas", escribe: "A fines de 1964 hice una investigación desordenada sobre el caso de las Poquianchis y escribí un cartapacio de unas cien páginas que no es ni reportaje ni ensayo ni novela, que no me gustó cuando lo leí terminado y que no me sirvió de nada. En 1965 decidí que había que escribir una novela sobre el tema" (Ibargüengoitia 1979, p. 33). El cartapacio al que hace alusión es, claro está, el texto que acabamos de revisar. Es interesante que plantee como un problema la 
ambigüedad del género -ni ensayo ni novela- y decida, por lo mismo, hacer algo que le aporte mayor claridad, más certeza. Es decir, emprender un género, la novela, que ya conoce. La solución, sin embargo, no le funciona: "En 1970 trabajé varios meses con este fin -«trabajar» en esa época consistió en sentarme en el escritorio frente a una hoja en blanco y luego acostarme en el diván a esperar a que se me ocurriera una idea-. Con muchos trabajos produje unas ciento cincuenta páginas que luego tiré a la basura" ( $i d$.). Veremos ahora con mayor detalle este proceso de reescritura fallida. Para ello nos apoyaremos en la correspondencia que intercambió con Joy Laville y, asimismo, en sus cuadernos personales.

La primera carta que inicia el diálogo creativo entre la pareja es del 12 de abril de 1965, y dice: "Aquí te mando mi libro, a ver si te gusta" (Laville). Es posible que el libro fuera Los relámpagos de agosto, publicado un año antes en Joaquín Mortiz, o El libro de las Poquianchis, que, como hemos visto, acababa de terminar en ese mes de abril de 1965. Contamos únicamente con la correspondencia de Ibargüengoitia, por lo que es imposible conocer la reacción de Laville ante su libro. Por suerte, las cartas de Ibargüengoitia se vuelven cada vez más extensas y minuciosas en cuanto a su proceso creativo, e incluyen además datos autobiográficos interesantes. En noviembre de 1966 narra a Joy una comida con amigos en Texcoco, que terminó a las diez de la noche. De regreso en su casa, trabajó en una traducción de treinta cuartillas y en su novela: "Fue muy buena idea ir al mole, porque entre ayer y hoy escribí el mejor capítulo de la novela, que termina con el capitán Balona quitándole los calzones a Marta Baladro, entre unos árboles de huizache" (Laville). Los personajes han cambiado de nombre: de las hermanas González Valenzuela a las hermanas Baladro, clara señal de que se trata ya de un texto de ficción; no le importa respetar el referente histórico, los periódicos ni el expediente judicial. El espacio geográfico sigue, sin embargo, siendo el mismo; estamos ante la primera versión de su novela en los estados de Guanajuato y Jalisco. $\mathrm{Al}$ menos eso es lo que se puede inferir del siguiente comentario, incluido en una de sus cartas a Laville fechada el 2 de agosto de 1970, en la que, después de expresar gran frustración por no poder continuar con la novela ("Sigo pensando en cómo corregir la chingada novela"), Ibargüengoitia decide volver a los lugares del crimen, a Pedrones y a Concepción, en una suerte de rescate de la figura del cronista: "No tengo la menor 
idea de qué espero encontrar allí. Pero creo que en atolladero, como en el que estoy, hay que buscar soluciones donde aparezcan" (Laville). Tenía la confianza de inventar los nombres de los personajes, pero seguía buscando la inspiración en los espacios históricos, reales, del crimen; en su intento frustrado por desatar la novela, se pone de manifiesto que aún estaba en la encrucijada de la ficción y la historia/ crónica $^{10}$.

La solución al impasse podría ser el narrador, quien entrevistaría a las hermanas Baladro, a Simón (Juan González Martínez, en el expediente) y a la Calavera con el afán de aclarar los crímenes. Esto escribió Ibargüengoitia a Joy Laville:

Presentar primero a las Baladro \& Co. en la cárcel, y haciéndolas hablar de cómo ocurrieron los diferentes sucesos. Por otro lado, tener una voz sólida y constante -la del narrador- con paréntesis, que son las voces de los interrogados -como Simón, la Calavera, etc.-, creo que de esta manera quedaría wraped la novela ¿no crees?... (Laville).

Tenemos aquí el primer intento de una estructura narrativa que rompe con la linealidad de El libro de las Poquianchis. La crónica iniciaba con el descubrimiento de los crímenes y seguía el recorrido del narrador en la investigación de los hechos. La novela daría un salto al pasado, con retrospectivas alternadas, para acercarse gradualmente, con las voces de los personajes involucrados, al tiempo de la narración. Para la figura del narrador pensó en un principio en la voz de Paco Aldebarán, que aparecería después en su novela Estas ruinas que ves. Luego decidió regresar a la voz autobiográfica, la misma de sus cuentos: "El problema fundamental será encontrar un tono adecuado para la voz del narrador, que como te decía en mi otra carta, no es la de Paco, por ser demasiado joven, sino más bien como yo mero" (Laville). De nueva cuenta, se titubea ante las posibilidades que ofrece un género más veraz (voz autobiográfica) u

${ }^{10}$ La novela Los albañiles (1964), de Vicente Leñero, se publicó un año antes del primer borrador de Las muertas y trata, al igual que ésta, un tema policial: el crimen real o imaginario de un velador. Su estructura formal, sumamente compleja -monólogos superpuestos y una voz narrativa en tercera persona-, pudo servir de inspiración para que Ibargüengoitia intentara un proyecto narrativo más ambicioso y dejara de lado la crónica que ya había terminado, la cual, como hemos mencionado, contaba con un solo narrador en primera persona. 
otro que busca únicamente la verosimilitud (voz de un narrador: Paco). En esta tercera versión no resolvió el problema.

Tampoco pudo resolver el problema de la voz de los personajes que no constaban en el expediente más que de manera circunstancial. Esto lo podemos notar en su crónica, cuando escribe sobre una prostituta:

Trabajaba yo cuidando unos niños en el pueblo de T. y ganaba treinta pesos al mes. Una señora me preguntó si quería ir al pueblo de M. a ganar cuatrocientos en el mismo oficio. Acepté. Pero cuando llegué al pueblo de M. y a la casa donde iba destinada, me di cuenta de que no iba a ser el mismo oficio, porque vi unas mujeres en traje de baño (Early draft, p. 9).

Apenas es posible percibir la idiosincrasia de la mujer en su comentario sobre las mujeres "en traje de baño". Ibargüengoitia tendría, sin embargo, que idear las voces o entrevistar a los personajes para darles mayor presencia en la novela. No se decidió por una u otra opción. En entrevista para The Guardian, en 1983, con motivo de la publicación de su novela en inglés, comentó: "If I had been Truman Capote, I would have gone round and interviewed everybody, got many tapes, but I'm very bad at that, I'm very shy. So I invented the characters, they are composite images of different people I know" (cf. Herbert 1983). Ibargüengoitia no rescató la voz real de las involucradas en los crímenes, ni logró en esta versión recrear sus voces. De ahí que en una carta escrita el 2 de abril de 1972, dijera a Joy Laville: "Estoy escribiendo muy mal, leyendo peor y, en general, jodido" (Laville).

En el mes de agosto de 1973 ya había renunciado por tercera vez a su proyecto de novela sobre el caso de las Poquianchis y escribía Estas ruinas que ves, obra situada también en Guanajuato, de humor irónico. En el primer cuaderno de su nueva novela escribió, no obstante, la siguiente nota: "en casa de Ricardo Pórtico, la mujer lee El caso de las Baladro" (Notebooks, 1); y en la versión final, el narrador, Paco Aldebarán, mostraba gran interés en escribir un texto sobre las Poquianchis.

Concluida Estas ruinas que ves, volvió de nueva cuenta a Las muertas. Lo podemos comprobar en sus cuadernos de trabajo, con fecha de 1974, y en una carta escrita a Joy Laville, en que dice: "Mañana escribiré algo sobre el día de la madre y el viernes, si me atrevo, empezaré a escribir la 3a versión de la nove- 
la" (Laville). El primer cuaderno tiene como fecha el mes de octubre, por lo que la escritura del borrador debió de haberse concluido ese mismo mes. Hay que recordar que Ibargüengoitia usaba los cuadernos para hacer apuntes sobre un manuscrito ya terminado con el fin de señalar errores y la nueva ruta que debía tomar. Ibargüengoitia escribía el manuscrito de corrido, lo revisaba con ayuda de su cuaderno y volvía a escribir una nueva versión ${ }^{11}$.

En la versión de 1974, el espacio de Las muertas ya no era Guanajuato, sino Cuévano y el Estado de Plan de Abajo. Luis Palacios (2009) comentó a este propósito que Cuévano podía compararse a un espacio mítico, similar al de Comala o Macondo. También Ana Rosa Domenella (2009) observó que Cuévano era una ciudad sin precisión geográfica, porque con ella el autor podía desmitificar todas aquellas ciudades que se le parecieran. En ese sentido, el modelo era más bien Vetusta, de La Regenta de Leopoldo Alas -novela, por cierto, para la cual escribió un prólogo en la edición publicada por Porrúa en su colección "Sepan cuantos...". Asimismo, Matthew Sibley (2015) explicó el cambio de nombre como un acto con el que se intentaba confundir las fronteras entre lo real sugerido y lo ficticio con un espacio equívoco que los lectores (o una parte de ellos) reconocen como Guanajuato. Es decir, en un principio la crítica resaltó la fuerza poética, luego la crítica social y, finalmente, el propio acto de escritura. En nuestro caso, destacamos el hecho de que Cuévano daba mayor libertad para distanciarse de la crónica y de su particularidad local, y para recrear una novela con Las muertas. El primer apunte de su nueva libreta sobre las Poquianchis traza el plan de una estructura de la novela sin lugar a dudas mucho más compleja (en las analepsis y prolepsis) que la crónica, e incluso que sus otras novelas escritas hasta entonces. La estructura empieza con una "Primera parte: gozosa. Viento en popa" que narra el romance y los desencuentros entre Manuela y Simón; se describe la vida del

11 Tal método de escritura se puede comprobar a partir de su archivo y de los comentarios de Joy Laville (1985, p. 43): "Eso era normal ya que así trabajaba él, deteniéndose de vez en cuando y comenzando todo otra vez... Escribía con lápiz y le fascinaban todas las cosas que venden en las papelerías. Sus expedientes y cuadernos de notas eran también muy ordenados. Siempre acompañaba su trabajo en las novelas con un cuaderno de reflexiones sobre el desarrollo de la trama y sus personajes. Disfrutaba enormemente el largo proceso de escribir y reescribir sus libros". 
burdel: de la gloria a la caída. La segunda parte sería "La tormenta y después al pairo". Aquí suceden las muertes de Beto, el hijo de Delfina...; se descubren finalmente los cuerpos. En la tercera parte escribió: "Grotesca" (Artwork). Podemos suponer que esta última revelaría la incompetencia del sistema judicial, las mentiras de los periódicos amarillistas y de las víctimas.

El problema de la voz de los personajes seguía sin resolverse, pese a ser algo prioritario. Quería que se escucharan las voces de las víctimas y de las victimarias; buscaba una novela coral, compleja en sus narradores y en el uso del tiempo. En otro apunte escribió: "La historia se vuelve plural, muchas voces; compleja la cronología. Habrá textos narrados desde 10 años hasta 8 días antes del presente de la acción" (Artwork). Luego, en el último día del año de 1974, escribió en su cuaderno: "Pensamiento de fin de año: entre el viaje a la costa y la vida de Beto (también Simón, Juan González), se abre un capítulo intitulado "Almanaque de las Baladro»" (Artwork). Este Almanaque podría haber sido algo parecido al catálogo de ideas fijas cuevanenses, "con frases notables dichas por las hermanas, y sucesos de sus vidas, contados con mucha brevedad, que nos permitan esclarecer su personalidad" (Artwork). En lugar de que hablaran todas las prostitutas y las matronas, pensó intercalar en el Almanaque descripciones que de ellas hicieran sus clientes más queridos, una suerte de funeral imaginario realizado en las páginas del libro.

Según se advierte en sus cuadernos, cada capítulo contaría con un narrador distinto. El primero sería la Calavera, el segundo un Doctor y, por último, varias voces y documentos: "Hay que inventar (importante) una forma que permita presentar diferentes posibilidades en los motivos de los personajes. Y también presentar las diferentes versiones de un mismo acto" (Artwork). No sabemos si realizó este ejercicio de múltiples narradores. En el mismo cuaderno refiere ya a una tercera versión en la que ha decidido que el narrador debe intervenir lo menos posible. Ni Aldebarán ni la voz autobiográfica entrañaban la voz correcta; podrían servir de presentadores, de comentaristas o de ordenadores, pero si ellos narraban terminarían aleccionando o burlándose del caso. Ibargüengoitia deseaba evitar que el texto cayera en la sátira o en la tragedia. En un cuaderno con fecha del 6 de abril de 1975, es decir, varios meses después de haber terminado la tercera versión, vuelve al narrador Aldebarán: "El libro de las Baladro va a estar presentado, comentado 
y ordenado por Paco Aldebarán (yo: Estas ruinas)" (Artwork). Al mes siguiente, el 8 de mayo, ya había cambiado de opinión: "Nueva Tercera Versión. El narrador estará fuera de la novela. Es quien escribe la novela. La novela es una de las formas alternativas que puede tener el relato. $\mathrm{N}$ dirá: Esta parte podemos imaginarla así..." (Artwork). Cuando parece que ya ha encontrado la voz adecuada, tiene una duda sobre el inicio del texto, que responde al hecho de retomar esa voz humorística, irónica, autobiográfica, de sus escritos previos:

Lo que no sé es si conviene que el Narrador parta de un punto de desastre. Es decir, "el libro que no escribí", o "que no terminé". O si es preferible que lo empiece como si este fuera el plan original, y construya la narración con las historias, los datos y el invento novelístico. [Probablemente, sea preferible, pero más difícil] (Artwork).

El narrador sería alguien que ordenara el material para dar sentido a los acontecimientos: "Lo importante es no buscar más enredos, ni más mentiras, ni más inventos" (Artwork). Una voz cercana a la del cronista del nuevo periodismo, pero con la libertad para inventar lo que quisiera. No buscaría la empatía, ni establecer un puente de complicidad irónica con el lector:

Yesterday I came back from town (I went to Excélsior after I saw you take off and then had lunch at the Centro Yucateco) at about 15:00, and I started and read through the "Ruinas" in search of Paco. The trouble with Paco is that he is much younger than I am now. He is no more than 30 , and that limits his usefullness in the Baladro context (Laville).

El narrador en tercera persona, omnisciente, una voz seria y neutra por medio de la cual se expresaran los personajes y la acción de la novela, era una voz totalmente nueva para él. De ahí la dificultad para tomar la decisión, las dudas y los cambios, incluso cuatro meses antes de concluida la versión final.

En el año del 76 Ibargüengoitia escribió la versión definitiva de la novela. La inició con el pasaje de Simón, que narraba la manera en que Manuela balaceó y quemó la panadería. No sólo era un hecho extraordinario, sino que el propio Simón sería el detonador de la caída de las Baladro; era una bomba de tiempo que colocó al inicio del texto. Escribió las glorias del burdel, las variedades y la inauguración del casino. Escribió sobre 
las muertes y se detuvo en el caso de Blanca, el cual presentaba varias posibilidades: el narrador refiere la historia evocando a la Calavera; abre directamente con la Calavera; o junta los relatos de la Calavera, de un cliente (el Libertino), del álbum y "la descripción de la enfermedad a la curación" (Artwork). Terminó el borrador de la novela sin llegar al tercer capítulo, que todavía le generaba dudas. En su libreta escribió: "La diferencia fundamental entre esta versión y las anteriores, consiste en la introducción de EL TIEMPO DEL NARRADOR, es decir, la acción será vista desde un punto situado a diez años de distancia" (Artwork).

En ese mismo año del 76, Ibargüengoitia obtuvo una beca del International Writing Program de la Universidad de Iowa. Llegó acompañado de Joy Laville a Iowa City, el $1^{\circ}$ de septiembre de 1976: "al final de uno de los veranos más secos que recuerden los que viven en la región" (Planos y notas de Hicha). Debió de haber ocupado el tiempo de la estancia para escribir la última versión de su novela. Asumimos que, con la misma voz narrativa y la estructura temporal de su último borrador, narró el caso de la muerte de Blanca, agregando más detalles sobre su infancia, vida y enfermedad. Intercaló la narración clara y precisa de las muertes, las supuestas voces de las víctimas y los victimarios, que iban entre comillas. Esta separación fue la mejor estrategia para la ironía, ya que, puestas una junto a la otra, destacaban las expresiones apasionadas, apenadas y cursis de las voces coloquiales: "En las mesas, dicen las que la conocieron, su tema de conversación predilecto era lo mal que la había tratado el destino - «la vida me jugó chueco», decía con frecuencia” (Ibargüengoitia 2003 [1977], p. 108); "En la actualidad se refiere a Teófilo invariablemente como "el pendejo de mi cuñado»" (p. 122); "Confesó que al pararse en la puerta de la panadería, disparó contra los cuerpos, pero que la pistola calibre .45 «no la obedeció»" (p. 130). Además del entrecomillado, usó el discurso libre indirecto -la voz de los personajes intercalada en la del narrador sin un marcador textual, como las comillas- para el humor grotesco. Así, en la muerte de Blanca, una de sus amantes intenta revivirla (después de haber repasado su cuerpo paralizado con planchas hirvientes) con una Coca Cola. A Rosa, otra prostituta que padece fiebre, la Calavera quiere curarla con un té de orégano. En la historia de Blanca se dice: "Fue apartada de su familia con engaños, vendida y comprada, iniciada en la prostitución a los catorce años y sin embargo, todo parece indicar que fue feliz" (p. 82). 
Concluida la narración, Ibargüengoitia agregó un epílogo, apéndices y una foto de las Poquianchis del proyecto inicial. El género de la crónica y de la historia suele apoyarse en imágenes; es otra herramienta para sustentar la veracidad de lo narrado. Ahí las tenía, víctimas con victimarios, pero las mujeres de la foto ya no eran las de la historia, eran sus personajes, y cada lector debía imaginarlas con sus palabras, así es que les quitó el rostro. Escribió en su calendario de actividades de la Universidad de Iowa que había terminado su novela el 25 de noviembre de 1976 a las 12:30. Tenía 185 cuartillas escritas a máquina. Trece años habían pasado desde que se enteró del caso. Dos semanas después, escribió una carta a su amiga Ángela Gurría en la que confirmaba este hecho: "Ya terminé la novela y la mandé. En el momento de entregársela al empleado de correos sentí lo que han de sentir las madres cuando paren. Ahora estoy en la convalecencia con ganas de emborracharme hasta el fin de año"12.

\section{LAS MUERTAS}

La novela se publicó por Joaquín Mortiz en la Colección Nueva Narrativa Hispánica. La versión impresa tiene una voz narrativa en tercera persona y una estructura fragmentaria en la que el tiempo se construye con repetidas analepsis y prolepsis. En comparación con El libro de las Poquianchis, se pierde el referente histórico: cambian los nombres de los personajes, las hermanas González Valenzuela pasan a ser las hermanas Baladro y el espacio ahora es Cuévano. Otro detalle importante es el cambio en la voz de los personajes, que en Las muertas se intercala con la del narrador.

Ibargüengoitia, en entrevista para el diario Unomásuno, respondió a Ambra Polidori sobre su proceso de escritura, al cual se refirió como "difícil de principio a fin" (cf. Clippings). Armando Ponce (1977) escribió una reseña inteligente y elogiosa en el semanario Proceso en la que supo identificar el arduo balance entre el género periodístico, el detectivesco y "el lenguaje directo como resultado de un alto dominio de la palabra" (p. 61). Guillermo Sheridan (1977), en otra reseña para la Revista de la Universidad de México, destacó el gran manejo de la trama,

${ }^{12}$ He tenido acceso a esta carta gracias a la misma Da Ángela Gurría, quien amablemente me dejó verla y fotografiarla. 
"que precisa su área de acción en lo argumental y en lo decididamente funcional" (p. 41), sin caer jamás en la gratuidad. En la revista Vuelta, José de la Colina (1977) alabó la figura del narrador impasible, la prosa "ceñida y sobria", la fuerza y claridad de la historia. "Tal «humildad»-tal soberana humildad-es de agradecer en nuestros días en que se nos obliga a ser lectores profesionales, técnicos de la lectura de la novela" (p. 41).

Ángel Rama (1978), por su parte, escribió un texto crítico que sirviera como estado de la cuestión de su obra completa. Situó Maten al león y Los relámpagos de agosto como las primeras novelas en Hispanoamérica que trataron con ironía al personaje del dictador y el mito de la Revolución mexicana. La ley de Herodes y Estas ruinas que ves eran, en cambio, obras menores; la primera destacaba por su temática del medio cultural y la segunda por haber obtenido un premio internacional. Fue hasta la publicación de Las muertas cuando el proyecto, iniciado con la sátira de los grandes discursos y mitos, encontró su mayor fuerza y originalidad. Como en los casos anteriores, Ibargüengoitia tenía un documento histórico, pero, a diferencia de lo que antes había hecho, en esta ocasión guardó una distancia "voluntariamente neutra e informativa" que le permitió una doble lectura: "la de un tremolante y bárbaro episodio policial y la de un diagrama intelectual que interpreta con escepticismo y humor el sorprendente mundo de los seres humanos" (p. 11). Rama comparó a Ibargüengoitia con Juan Rulfo por su humorismo negro y el entorno social de miseria sobrecogedora, y con Jonathan Swift y José Guadalupe Posada por su "ironía amarga... compasiva y tierna" (id.).

Por último, dos años después de su publicación, en 1979, Octavio Paz escribió sobre Las muertas: "La risa es una defensa contra lo intolerable. También es una respuesta al absurdo. Una respuesta no menos absurda. Pues lo verdaderamente cómico es que todo sea como es; la maldad es doblemente terrible porque no tiene pies ni cabeza" (p. 368). De esta manera, Las muertas representó para Ibargüengoitia un gran capital literario con el que pudo contratar a Carmen Balcells como agente literario y proponer la novela para su traducción al inglés y al francés. En 1983, The dead girls se publicó de manera simultánea en Inglaterra y Estados Unidos, bajo los sellos editoriales Chatto \& Windus y Avon. El primero tenía una larga tradición por haber publicado a autores y libros canónicos de la literatura inglesa; había, de hecho, comprado Hogarth Press -la editorial del grupo de 
Virginia Woolf. En ese momento, le interesaba una colección de autores extranjeros en la que participaran, entre otros, Italo Calvino. El segundo, en cambio, tenía por cometido llegar al gran público con autores de escritura entretenida. El hecho de que Ibargüengoitia fuera aceptado en ambas editoriales revela mucho de su poética y de su genio.

Si bien la recepción de su obra no fue masiva en el mercado anglosajón, sí recibió reseñas en los mejores suplementos de Inglaterra: The Guardian, The Observer, The Daily Telegraph, Tribune y The Times Literary Supplement. Hermione Lee describió la novela como una comedia negra sumamente emocionante de un autor que, a pesar de su apellido impronunciable, sería desde ahora conocido por todos los lectores ingleses; Selina Hastings la alabó como una novela de formidable poder; Norman Shrapnel, como un libro infinitamente entretenido; Nicholas Rankin, como un libro excepcionalmente bueno; y por último, en Tribune describieron a Ibargüengoitia como un autor de mirada cínica, de juicio sereno y preciso. Más importante aún, en la contraportada se publicó el comentario que Salman Rushdie dedicó a la novela en Chatto \& Windus:

The extremely high quality of this novel arises out of Ibargüengoitia's remarkable ability to see the overheated components of his tragedy-cynical madams, corrupt soldiers, cheapjack politicians, indolent pimps, violent crimes, bodies in the back yard- with a cool dissecting eye that is somehow neither amoral nor hip. The Dead Girls is a startlingly good book by an author of genuine, exciting originality (Ibargüengoitia 1983).

Según Charlotte Lange (2009) y Cathy Fourez (2010), Ibargüengoitia logró con Las muertas una variante original de la novela negra y una parodia del nuevo periodismo o crónica literaria. El género del nuevo periodismo intentó en su momento conjuntar la verdad con la ficción, la nota periodística con la literatura. Para ello, Thomas Wolfe identificó cuatro características esenciales del nuevo género: "1) scene-by-scene construction, 2) the recording of dialogue in full, 3) third-person point of view, and 4) the detailed recording of everyday customs and surroundings as adapted from the nineteenth-century realist novel" (apud Lange 2009, p. 3). Estas cuatro características formales buscaban suspender la incredulidad del lector para trascender a un mundo sin fisuras, incuestionable en su 
verdad. Ibargüengoitia dio un paso más al pedir del lector el rechazo sistemático de la credulidad. El pacto de lectura era así notablemente más complejo porque implicaba una actitud más crítica y participativa del lector. El narrador de Las muertas busca la objetividad del hecho histórico, pero nunca la logra del todo. Desde el epígrafe se nos indica: "Algunos de los acontecimientos que aquí se narran son reales. Todos los personajes son imaginarios" (Ibargüengoitia 2003 [1977], p. 7). Luego, la primera frase de la novela, "Es posible imaginarlos" (p. 9), revela la estrategia que se usará en todo el texto, en que el narrador intenta, sin éxito, pasar desapercibido. Al invitar al lector a imaginar, creer, pensar; al organizar las escenas sin obedecer un orden cronológico; al interrumpir la narración con citas de documentos y testimonios supuestamente veraces; al imaginar diálogos y los espacios de la acción, el narrador parodia las convenciones del nuevo periodismo.

Si regresamos a la primera versión, El libro de las Poquianchis, vemos que en ambos casos la voz del narrador cuestionaba esta conexión entre historia y ficción, pero mientras que en el primer caso lo hacía con la voz autobiográfica de un cronista más o menos fallido -consultó el testimonio, pero por pocas horas; se informó en los periódicos del caso, pero no entrevistó a las involucradas-, en el segundo tenemos a un narrador omnisciente, en tercera persona, que subvierte su autoridad con las estrategias formales ya descritas. Vimos que, en el transcurso de trece años, el narrador pudo ser Paco Aldebarán, un joven profesor de literatura que narra Estas ruinas que ves, o la voz autobiográfica de La ley de Herodes. Finalmente, optó por una tercera alternativa que, podemos asumir, le dio mayor libertad para incluir las voces de los personajes, el expediente y otros documentos. El relato que constituye El libro de las Poquianchis tiene una estructura lineal, mientras que en Las muertas nos encontramos con una estructura fragmentaria. Como hemos podido ver en los cuadernos, el cambio responde a su decisión de escribir una novela en lugar de una crónica. Desde la primera versión novelística, Ibargüengoitia piensa en una analepsis que suceda al encuentro entre el narrador y las Poquianchis. Después crea nuevos saltos temporales hasta llegar a la versión última, que conecta una acción fuera del tiempo narrativo (pero que será clave para el encarcelamiento de las Poquianchis) al final de la novela. Hay pues una conexión circular diegética en la cual cada capítulo establece una analepsis o una prolepsis. 
Si el nuevo periodismo quería dar una imagen de temporalidad lineal evolutiva y, por lo mismo, irreversible, con Ibargüengoitia tenemos un tiempo plural, confuso, al que el lector debe dar sentido.

El pacto de lectura implica, en todas las versiones, una superposición de los planos histórico y ficticio. Si bien el lector de $\mathrm{El}$ libro de las Poquianchis debe cuestionar los hechos narrados atribuyendo la verdad al narrador autobiográfico, en Las muertas -y en las versiones sugeridas en los cuadernos- la desconfianza se centra en la figura misma del narrador. El resultado es, por tanto, más complejo. Podemos desconfiar de los supuestos logros y de las declaraciones de un escritor que se aboca a una investigación histórica. Pero en el segundo caso, en la versión definitiva de Las muertas, se duda y se cuestiona el propio acto de narrar. En respuesta a las críticas sugeridas por Hayden White contra la supuesta pérdida de rigor de una historia que usa las herramientas literarias, Ivan Jablonka (2016, p. 146) responde:

Contar un acontecimiento es, inseparablemente, explicarlo y comprenderlo, responder a un cómo y un porqué que lo hacen apropiable desde un punto de vista intelectual. Un relato es, pues, en sí mismo, una explicación. A la inversa, una historia enrevesada... que se lanza en todos los sentidos, no es un relato. La narración, por lo tanto, no es el yugo de la historia, su mal necesario; constituye, al contrario, uno de sus recursos epistemológicos más poderosos.

Creemos que Ibargüengoitia confirma las ponderaciones de Jablonka, a la vez que ratifica la siguiente conclusión: "El investigador no pide al lector la suspensión voluntaria de la incredulidad, sino el rechazo sistemático de la credulidad" (p. 247).

Tenemos, por último, el cambio del final del relato. El libro de las Poquianchis se resuelve en una suerte de moraleja escrita con un tono irónico, que reparte culpabilidades y propone soluciones; la más evidente es legalizar la prostitución "y dignificarlas. Darle cabida en el Registro de Profesiones, crear un arancel y un Sindicato de Prostitutas, hacer a éstas beneficiarias del Seguro Social, fundar una Escuela de Madrotas y exigirle título a quien pretenda dedicarse a eso". Otra opción es "abolir la prostitución y convencer a las mujeres mexicanas de que para llegar a la cama no hace falta un romance apasionado de dos o tres años" (Early draft, p. 96). Por un lado, un problema 
institucional y, por otro, uno de costumbres. En la novela tenemos, en cambio, un final abierto: las víctimas caminan hacia la luz del atardecer después de haber comido mole, compensación por los crímenes perpetrados en su contra: "En el atrio, las mujeres se despidieron y se fueron cada una por diferente camino" (Ibargüengoitia 2003 [1977], p. 146). No sabremos nunca qué fue de ellas.

La crítica social en la novela se encuentra en el último apéndice, empleado para describir el libro de contabilidad de Arcángela Baladro. En una parte están los nombres de los clientes deudores y en otra los sobornos a las autoridades municipales: "Por ejemplo, diez pesos diarios a los policías que estaban de turno en la cuadra, sesenta al Presidente Municipal, sesenta al inspector de policía, etc." (id.). Así, para el género de la crónica, relacionado de manera más directa con la coyuntura histórica, se presenta un final con soluciones concretas en el campo de la política y de las costumbres, mientras que, en la novela, cuyo referente social se supone más diverso e incluso atemporal, el final representa una interrogante.

Para Cathy Fourez, Las muertas y Dos crimenes son una variante original de la novela negra que se escribe en México, cuyos rasgos principales son: las investigaciones azarosas de la policía, que en la mayoría de los casos terminan por ser inservibles; la figura del detective improvisado, que muchas veces recae en el narrador; la sociedad afectada por la corrupción, el autoritarismo y el periodismo amarillista; y los asesinatos seriales de mujeres. De esta manera, cuando Paco Ignacio Taibo II refirió los antecedentes del neopolicial en México citó tres novelas, dos de las cuales eran Las muertas y Dos crímenes (la otra fue Los albaniles de Vicente Leñero). La diferencia con Raymond Chandler, cuyos escenarios están forjados de corrupción e injusticia, es de grado. Lo que en él se convierte en desilusión e individualismo de un detective inolvidable, con Ibargüengoitia se vuelve humor grotesco ${ }^{13}$. El humor grotesco carece de una explicación clara, genera una impresión de pasmo, repugnancia y sorpresa. Hay en él un distanciamiento con el mundo que tiene sentido; no aporta un desenlace cerrado; no hay una cifra por descubrir. Así pues, en Las muertas se desarrolla una crítica a varias entida-

13 Domenella (2011, p. 202) analiza en la obra de Ibargüengoitia el cambio de un humor "irónico y gozoso" a otro "sombrío y grotesco" después de Las muertas. 
des que conviven en el libro: la justicia mexicana, la ignorancia de las clases pobres, la doble moral de la clase política, la ética mojigata de provincia, la corrupción en todas las capas sociales. Y, en el centro de la historia, hay una risa grotesca que impide una condena o una empatía con el otro ${ }^{14}$.

\section{Conclusiones}

Las muertas es una novela que le llevó a su autor trece años de ponderaciones y borradores diversos. Más allá del esfuerzo que este tiempo refleja, y del éxito en la recepción de la crítica literaria y académica, de su consagración en el campo literario nacional e internacional, nuestro enfoque en este artículo ha intentado demostrar que esta novela es, en realidad, varias novelas. Desde la primera versión de 1965, ideada como una crónica, hasta su transformación en la década de los años setenta en una novela de estructura compleja con distintos narradores (en primera y tercera persona), Ibargüengoitia cuestionó siempre la frontera entre la ficción y la historia, la realidad y lo imaginario; realizó una crítica al periodismo amarillista y a la justicia mexicana. Desde los años setenta, cuando decidió escribir una novela que potenciara los alcances de la ficción a partir del material, buscó la complejidad formal de la trama que mantuviera en suspenso al lector y, además, abandonó el humor irónico para adoptar un tono grotesco.

Sus herramientas de trabajo revelan, en gran medida, la naturaleza de sus desafíos. Sus cartas a Joy Laville, en las que ahonda en la trama y en la búsqueda del narrador, revelan la

14 Otro estudio significativo de la novela es el realizado por KARIM BENMiloud (2007). El estudioso comenta de manera breve la apuesta formal de Las muertas, ya descrita por Charlotte Lange, para centrarse después en el tema de la prostitución, cuyo tratamiento revela el sistema machista, violento y misógino que permea la totalidad de la sociedad mexicana, desde las élites políticas y las autoridades judiciales hasta los policías. El apellido de las madrotas, Baladro, significa el grito o alarido en contra de esta sociedad. Resulta también significativo que el burdel de El Casino del Danzón se inaugure el 15 de septiembre. La libertad del país representa, al mismo tiempo, la esclavitud de las mujeres. El enigma, que en otras novelas neopoliciales se revela con la identidad del asesino, aquí se resuelve en el último apéndice ("El libro de Arcángela"), en que aparece la contabilidad del burdel. El responsable es el dinero, que compra a policías y a autoridades políticas, además de esclavizar a mujeres para comerciar con ellas. 
necesidad de la crítica de alguien que, al igual que él, era una creadora. En este texto que escribió para una exposición de Joy Laville en 1973, podemos encontrar ecos que remiten a su propia obra de novelista:

Ella pasa entre cinco y siete horas diarias frente a un cuadro, haciéndolo, y otras dos o tres contemplándolo y haciendo gestos de esos que dice que hacen los pintores, que consisten en cerrar un ojo y hacer ángulos con los dedos para transportar las distancias y estudiar la composición... Una de las cosas que más me gustan de mi mujer, como pintora, es que no dice frases célebres. Nunca la he oído exclamar, por ejemplo, "iyo lo que quiero expresar son las fuerzas telúricas", o peor: "pinto porque me duele la vida", etc... Es una pintora sin trucos, sin moda, sin doctrina. Ni protesta ni acepta. Hace lo suyo, con gran talento (Textos varios).

Es esta persona la que, imaginamos, le servía de interlocutora al escribir sus novelas. Para Ibargüengoitia, la lectura de alguien así, interesado en el dominio de la técnica, con el conocimiento de la tradición creadora que se apropiaba sin frases solemnes, debió ser importante.

De igual manera, el cuaderno nos evoca sus años de estudiante de Ingeniería, de alguien que, al crear o probar una máquina, apunta en su cuaderno los problemas del mecanismo y la manera de resolverlos. No hay en estos cuadernos una poética, una posible interpretación de su texto o una referencia intertextual: son todos reportes prácticos que atañen a puntos muy específicos de los problemas que plantea el texto ${ }^{15}$. Estamos acostumbrados a desconfiar del entretenimiento, pero como indica el novelista Michael Chabon (2009, p. 2): "The brain is an organ of entertainment, sensitive at any depth, and over a wide spectrum. But we have learned to mistrust and despise our human aptitude for being entertained, and in that sense we get the entertainment we deserve”. Ibargüengoitia busca las herramientas y artificios para narrar la novela, de manera que capte

15 Escribió estos cuadernos para casi todas sus novelas. Por ejemplo, en uno de ellos, correspondiente a 1978, anota sobre Dos crimenes: "En esta versión se ve ya más clara la novela, sobre todo aparece la parte de Marcos". Y también: "el capítulo puede estar construido como un paseo de Dante y Virgilio por la vida y propiedades de Ramón Tarragona. Termina este capítulo con la abertura (por primera vez en el libro del tema de la herencia)". Y, por último: "Si la parte de Marcos está narrada por Marcos, la de don Pepe tiene que estar narrada por don Pepe" (Dos crímenes 1977-1979). 
la atención e interese al lector. En una palabra, busca el entretenimiento con la complejidad del gran arte.

\section{REFERENCIAS}

Artwork. Jorge Ibargüengoitia Papers, C1334, Manuscripts Division, Department of Special Collections, Princeton University Library.

Batis, Huberto 1979. "El mundo de los libros", Sábado, suplemento de Unomásuno, 22, octubre.

Benmiloud, KARIM 2007. "Las muertas de Jorge Ibargüengoitia: contraintes, violences et maisons closes", CRIMIC, Sorbonne, pp. 1-9.

Chabon, Michael 2009. Maps Eं legends. Reading and writing along the borderlands, Harper, New York.

Clippings. Jorge Ibargüengoitia Papers, C1334, Manuscripts Division, Department of Special Collections, Princeton University Library.

Colina, José de la 1977. "Las muertas de Jorge Ibargüengoitia”, Vuelta, 1, 12, noviembre, pp. 40-41.

Cuartas, Juan Pablo 2018. "Archivo y escritura semoviente en Mario Bellatin”, en Bellatin en su proceso: los gestos de una escritura. Coords. Alejandro Palma Castro, Alicia V. Ramírez Olivares, Alejandro Lámbarry y Samantha Escobar Fuentes, Prometeo Libros, Buenos Aires, pp. 199-216.

Domenella, Ana Rosa 2009. "Jorge Ibargüengoitia, de la ironía a lo grotesco. Otro modo de narrar amores y crímenes”, en Homenaje y diálogo. Primer Coloquio Nacional de Literatura Jorge Ibargüengoitia. Memoria. Comps. Norma Angélica Cuevas, Ismael M. Rodríguez y Elba M. Sánchez Rolón, Universidad de Guanajuato, Guanajuato, pp. 183-207.

Domenella, Ana Rosa 2011. Jorge Ibargüengoitia: ironía, humor y grotesco. "Los relámpagos desmitificadores" y otros ensayos críticos, El Colegio de MéxicoUniversidad Autónoma Metropolitana-Iztapalapa, México.

Dos crimenes 1977-1979. Jorge Ibargüengoitia Papers, Manuscripts Division, Department of Rare Books and Special Collections, Princeton University Library.

Early draft. Jorge Ibargüengoitia Papers, C1334, Manuscripts Division, Department of Rare Books and Special Collections, Princeton University Library.

Fourez, CATHY 2010. Les traitements du genre policier chez Jorge Ibargüengoitia. Une écriture en flagrant délit, Éditions universitaires européennes, Sarrebruck.

Goldchluk, Graciela 2011. El diálogo interrumpido: marcas de exilio en los manuscritos mexicanos de Manuel Puig, 1974-1978, Universidad Nacional del Litoral, Santa Fe (Argentina).

Herbert, Hugh 1983. "Hugh Herbert meets the Mexican novelist, Jorge Ibargüengoitia. No holds barred", The Guardian, 18 de marzo.

IbARgüEngoITIA, JoRge 1979. "En primera persona: «Memorias de novelas»", Vuelta, 3, 29, abril, pp. 32-34.

Ibargüengoitia, Jorge 1983. The dead girls. Trans. A. Zatz, Chatto \& Windus, London. 
IbARgüengoitia, Jorge 2003 [1977]. Las muertas, Joaquín Mortiz, México. Jablonka, Ivan 2016. La historia es una literatura contemporánea. Manifiesto por las ciencias sociales, Fondo de Cultura Económica, México.

Lámbarry, Alejandro y Samantha Escobar 2018. "El enigma circular: postergación y variación de la resolución del enigma en Flores de Mario Bellatin”, en Bellatin en su proceso: los gestos de una escritura. Coords. A. Palma Castro, A.V. Ramírez Olivares, A. Lámbarry y S. Escobar Fuentes, Prometeo Libros, Buenos Aires, pp. 217-316.

LANGe, Charlotte 2009. "The «truth» behind a scandal: Joge Ibargüengoitia's Las muertas", Neophilologus, 93, 3, pp. 1-16.

Las muertas. Jorge Ibargüengoitia Papers, C1334, Manuscripts Division, Department of Rare Books and Special Collections, Princeton University Library.

Laville, Joy. Jorge Ibargüengoitia Papers, C1334, Manuscripts Division, Department of Rare Books and Special Collections, Princeton University Library.

Laville, Joy 1985. "Llevaba el sol adentro. Imágenes de Jorge”, Vuelta, 9, 100 , marzo, p. 43.

Lejeune, Philippe 1996. Le pacte autobiographique, Éditions du Seuil, Paris.

MuÑoz, Alicia 2008. "The language of female violence in Jorge Ibargüengoitia's Las muertas", Arizona Journal of Hispanic Cultural Studies, 12, pp. 79-92; doi: 10.1353/hcs.0.0040.

Notebooks (1). Jorge Ibargüengoitia Papers, C1334, Manuscripts Division, Department of Rare Books and Special Collections, Princeton University Library.

Palacios, Luis 2009. "Jorge Ibargüengoitia, cambio de perspectiva de Guanajuato a Coyoacán”, en Homenaje y diálogo. Primer Coloquio Nacional de Literatura Jorge Ibargüengoitia. Memoria. Comps. N.A, Cuevas, I.M. Rodríguez y E.M. Sánchez Rolón, Universidad de Guanajuato, Guanajuato.

Paz, Octavio 1983 [1979]. "Una novela de Jorge Ibargüengoitia”, en Sombras de sombras, Seix Barral, Barcelona.

Planos y notas de Hicha. Jorge Ibargüengoitia Papers, C1334, Manuscripts Division, Department of Rare Books and Special Collections, Princeton University Library.

Ponce, Armando 1977. "De las Poquianchis a Las muertas", Proceso, 39, $1^{\circ}$ de agosto, pp. 61-62.

Ponce, Bernardo 1964. "Consignación de «Las Diabólicas»", Excélsior, 20 de enero.

RAMA, ÁngEl 1978. "Jorge Ibargüengoitia. Un Posada de la literatura mexicana”, Sábado, suplemento de Unomásuno, 59, 30 de diciembre, pp. 10-11.

SHERIDAN, GUILleRmo 1977. "Las muertas de Jorge Ibargüengoitia", Revista de la Universidad de México, 31, 12, p. 41.

Sibley, Matthew 2015. La trilogía del "Plan de Abajo" de Jorge Ibargüengoitia: un cuestionamiento de la realidad y la ficción a partir del espacio quimérico, las técnicas narrativas y la heteroglosia, tesis, Bowling Green State University, Bowling Green, OH.

Textos varios. Jorge Ibargüengoitia Papers, C1334, Manuscripts Division, Department of Special Collections, Princeton University Library. 
Villaseñor, Margarita 2002. "Conversaciones frente al mar de la presa", en Jorge Ibargüengoitia, El atentado. Los relámpagos de agosto. Ed. crít. de Víctor Díaz Arciniega y Juan Villoro, ALLCA XX-Université Paris X, Nanterre-Madrid, pp. 401-405. (Colección Archivos, 53). 
